\title{
Metahistoria de Hayden White * y las aporías del «giro lingüístico»
}

\author{
ELÍAS JOSÉ PALTI \\ Universidad de California
}

Con considerable retraso llega al público de habla castellana una obra cuya aparición, en 1973, marcó un hito en el desarrollo de la "nueva historia intelectual" en Estados Unidos, dando un impulso decisivo a lo que hoy se ha dado en llamar en dicho país el "giro lingüístico» que domina a la subdisciplina. Sin duda alguna, Metahistoria sigue siendo allí la obra más influyente entre aquellos historiadores que intentan reflexionar sobre el tipo de estrategias narrativas que la escritura histórica envuelve en tanto que forma de expresión literaria. El aporte unánimemente reconocido de Hayden White 'radicaria en su mismo intento por supcrar las clasificaciones hasta entonces usuales de cscuelas históricas según las respectivas filiaciones ideológicas o filosóficas (lo que supone una focalización exclusiva en la dimensión referencial del lenguaje) a fin de elaborar una tipología de los estilos historiográficos sobre la base de las formas de los discursos históricos. En dicha empresa destinada a penetrar en la «estructura profunda» que subyace, y articula, según postula, todo relato coherente de los acontecimientos del pasado, White traslada, pues, su enfoque del plano de los contenidos al de las formas del pensamiento histórico y, dentro de éste, del de la lógica al de la retórica?

Siguiendo antiguas poéticas y modernas teorías del lenguaje, White comienza por clasificar tropológicamente los «actos de prefiguración» o estándares pre-conceptuales (ade naturaleza genéricamente poé- tica, y especificamemte lingüistica») en los que, afirma, toda narrativa histórica, en tanto «artefacto literario», se funda ${ }^{3}$. Tales tropos, que White clasifica en metonimia, sinecdoque, metáfora e ironía, provcerían el protocolo lingǘstico de base a las diver. sas formas de relato histórico. Los distintos estilos historiográficos que este autor analiza representarian un nivel superior de formalización de las prefiguraciones poéticas que les preceden, y surgen de su articulación en algún tipo de «estrategia» mediante la cual se logra finalmente el «efectivo explicativo». En la estructura de tales estrategias explicativas White distingue tres instancias fundamentales, las que denomina «argumentación formal», «implicación ideológica» y spuesta en trama» (emplotment) ${ }^{4}$.

Sobre esta grilla clasificatoria White analiza las obras de historiadores (Michelet, Ranke, Tocqueville y Burkhardt) y filósofos de la historia (Hegel, Marx, Nietzsche y Burkhardt) del siglo xix. De este modo, este autor conjuga (y éste sería el segundo de sus aportes) los desarrollos teórico-metodológicos con su aplicación al análisis de discursos historiográficos concretos. Pero el rasgo más caractcrístico de su metodología consiste en su particular «estrategia explicativa» (para definirla con sus propios términos) que combina tal aproximación tipológica, de corte «formalista», con una perspectiva relativista o «irónica» respecto del valor cognitivo de toda empresa historiográfica. En términos

* Hayden White, Mtahistoria. La imaginación histónca en la Earopa dal sizto xx, México, FCE, trad. S. Mastrangello, 1992. 
de Kuhn, los diferentes paradigmas historiográficos que White describe serían inconmensurables entre sí. El resultado scrá una taxonomía perfectamente llana, sin ninguna clase de jerarquías internas (contrariamente a lo que toda taxonomia, en principio, supone).

Mi método, en resumen, es formalista. No trataré de decidir si la obra de determinado historiador es un rclato mejor, o más correcto, de determinado conjunto de acontecimientos o segmento histórico que el de algún otro historiador; más bien, trataré de identificar los componentes estructurales de tales relitos (p. 14)

La combinación de ambos enfoques le pcrmitiría, pues, a este autor, penetrar la coherencia específica que distingue a cada relato, evitando, a la vez, cualquier juicio de valor en cuanto a la respectiva legitimidad a ser proclamado como el «verdadero». De ello se sigue, afirma White, que, aun cuando la historia bicn pueda considerarse como constituida por un conjunto de «artefactos literatios", tampoco los así llamados «historiadores narrativistas» (cuya perspectiva se funda en el tropo de la ironia) tendrian privilegio alguno en dictaminar cómo se debe escribir lú historia. Pretender esto implicaría la paradoja de convertir la propia ironía en un valor absoluto.

White evitaría tal «falacia normativista ${ }^{5}$ mantenićndose en un plano estrictamente descriptivo. Es precisamente por medio de «ronizar la ironía que este autor pretende «trascender» la misma y superar las consecuencias relativistas que ésta conlleva.

Si se pudiera demostrar que la ironía es sólo una de una serie de perspectivas posibles de la historia, cada una de las cuales tiene sus buenas razones para existir en un nivel poético y moral de conciencia, la actitud irónica habría empezado a despojarse de su status como perspectiva necesaria para la contemplación del proceso histórico. (p.412)

Así reformulada, White habría resuelto una problemática común a todas las filosofias post-lluministas de la historia, a saber, la de «cómo convivir con una historia explicada y tramada de modo irónico, sin caer en la condición de desesperación de la que Nietzsche escapó sólo por medio del irracionalismo» (p. 359): mediante un textualismo radical White lograría volver los argumentos relativistas contra sí mismos. Hecho esto, se descubre enlonces que «somos libres de concebir la historia como nos plazca", bastando, pues, con "nuestra voluntad de ver la historia desde una perspectiva anti-Irónicas para trascender el punto de vista del agnosticismo como la única forma "realista» de ver el mundo (p. 412).

White culminaba de esta forma una búsqueda persistente, iniciada en $1959 \mathrm{con}$ su escrito sobre Aben Jaldún ${ }^{6}$, y continuada hasta hoy a través del estudio de las más diversas escuelas historiográficas, orientada a condenar al mismo tiempo toda forma de relativismo y determinismo (ambas igualmente pesimistas respecto del potencial transformador de la praxis histórica), y a reafirmar, según apunta $H$. Kellner, wa libertad humana destacando la fuerza creativa del lenguajes ${ }^{7}$.

No todos, sin cmbargo, han considerado a su empresa metahistoriográfica igualmente exitosa; algunos, siquiera legítima. Tanto su tipologia, como su actitud irónica, terminando por su "decisionismo", han sido objeto de la más variadas y severas críticas ${ }^{*}$. La verdadera ironía de esta obra quizás consista en que, a pesar del indudable impacto que produjo su publicación, haya sido cuestionada, con perfecta simctría, tanto por quienes leyeron la misma como abogando por un esteticismo que conduciria, necesariamente, a un relativismo absoluto (dado que en ella se rechaza 
explicitamente la posibilidad de validar intersubjetivamente una determinada perspectiva histórica, siendo que su aceptación o rechazo se fundaría puramente en consideraciones pre-críticas), así como por quienes, por el contrario, creyeron ver en la metahistoria whiteana un resabio (de matriz estructuralista) de la ansiedad metafísica por una epresencia total». Cabe suponer, por otro lado, que ambos tipos de críticas encontradas no pueden deberse, sin embargo, a una lamentable sucesión de malentendidos. Conviene detenerse, pues, en el análisis de csta obra ya que en ella, como veremos, habrán de revelársenos una seric de aporías, inherentes, por otro lado. al llamado «giro lingüístico».

En el prescntc cstudio ensayaremos, sin embargo, un modo de aproximación crítica a la obra de White algo distinta a la intentada hasta ahora. Ambas líncas de ataque ya mencionadas a Metahistoria apuntan a revelar la existencia de controversias fundadas en diferencias de nivel en las premisas de análisis". Aquú, cn cambio, intentaremos lo que suele llamarse una crítica «inmanente»; es decir, irataremos de desentrañar aquellas tensiones que en la misma obra se manifiestan, partiendo, para ello, de la aceptación previa de la metodología de análisis que el propio autor propone ".

Como White muestra, algunas de las combinaciones lógicamente posibles en su taxonomía no resultan, sin embargo, con. sistentes de hecho. Entre los diversos modos de tramar, de argumentación formal y de implicación ideológica se establece lo que White llama «afinidades electivas", y también incompatibilidades. Ial sería cl caso del modo «satírico» de «puesta en traman, el cual se adecua a los modos de ideologia liberal o conservador, pero nunca al radical. Pues bien, la propia metodología de Whitc encierra una especie de incompatibilidad similar, dado que no hay modo, como veremos, de hacer concurrir, como él intenta, un modo de argumentación de tipo formalista con un estilo irónico (ver cuadro adjunto).

\section{Fornalismo: Entre la «Pura Contingencias y Ia "Pura Determinación"}

Primeramente, vamos a examinar los diferentes argumentos por los cuales White intenta validar su modelo.

Toda taxonomía supone una fundamentación de tipo analítico, dado el tipo de operaciones intelectuales que implica. Fundadas en una pura combinatoria lógica, los sistemas clasificatorios se orientan a distinguir y definir a priori el conjunto de objetos virtuales existentes en un dominio dado. Los sistemas lévi-strausseanos de parentesco son un ejemplo de tal modo de operación conceptual. El campo respectivo es así transformado en su totalidad en un sistema deductivo resultante del despliegue lógico de una racionalidad a priori. En el caso del campo historiográfico, su rango de variabilidad estaría delimitado por la naturaleza misma del «lenguaje poético en general'.

Al presentar mis análisis de la obras de los principales pensadores históricos del siglo xix en el orden en que aparecen, he intentado sugerir que su pensamiento representa la elaboración de la posibilidades de prefiguración tropológica del campo histórico contenidas en el lenguaje poético en general (p. 11).

Para Whitc, pues, la aparición o desapaparición de los estilos historiográficos son hechos históricos, pero no los estilos mismos. Éstos corresponderian a arquetipos universales, los cuales tienden a desplegarse en el tiempo y en el espacio. La descripción que hace White de dicho proceso recuerda los corsi y ricorsi de Vico ", tha recurrencia cíclica de tropos que actúan al modo de causas fomales ${ }^{12}$ del desarrollo historiográfico ${ }^{13}$. 
Sin embargo, esta apelación característica de White a los esquemas formales se revclará problemática. Su relativismo e historicismo al nivel historiográfico parece condueir aquí a su opuesto al nivel metahistoriográfico. Tal fundamentación analítica de su proyecto taxonómico se basa en consideraciones de corte sustancialista y a-histórico. En este caso, su «formalismos no parece dejar ya lugar alguno a la «ironía». La única justificación posible de sus procedimientos clasificatorios, conservando, a la vez, su actitud irónica hacia ellos, residiría en apelar al argumento convencionalista.

White, efectivamente, procura superar las consecuencias dogmáticas que su formalismo conileva relativizándolo y afirmando la naturaleza instrumental de su taxonomía. Ésta se trataría, pues, de una mera herramienta intelectual. Consecuentemente, al igual que los diversos discursos históricos que él analiza, su metahistoria no pretendería reclamar ninguna prioridad sobre otras metahistoriografias alternativas posibles. La actitud irónica, se expande asi para comprender tambićn este segundo nivel (metahistoriográfico) de conceptualización.

De hecho, su esquema contiene un grado inocultable de arbitrariedad y algunas de las categorias que White utiliza han sido conscientemente redefinidas ad hoc ${ }^{14}$. Sin embargo, cuando White avanza en su actitud irónica, sus esfuerzos taxonómicos empiezan a perder sustento. ¿Cuál es entonces su sentido y rendimiento específico? El intento de White por justificar, aunque sólo en una nota a pie de página ${ }^{15}$, convencionalmente sus procedimientos, es decir, esgrimiendo su utilidad para el análisis de las obras en cuestión, no alcanza a responder a dicha pregunta. No se trata simplemente del hecho obvio de que la utilidad de su tipología pueda ser ( $\mathrm{y}$, de hecho, lo ha sido) materia de controversia, Tampoco importa tanto el que haya incluso quienes argumenten, con buenos fundamentos, que la misma parece mucha veces un mero juego verbal que no aporta ninguna contribución real ni alumbra aspectos en las obras que estudia oscurecidos por las aproximaciones "tradicionales" ${ }^{16}$; 0 , peor aún, que su tipología resultaría excesivamente rigida como herramienta conceptual, obligando reiteradamente a su autor a forzar los sistemas de pensamiento que trata a fin de adecuarlos a sus moldes preconcebidos ${ }^{17}$. El punto verdaderamente crítico radica en que, como White sostiene, no existiría ya un "campo neutral» en el cual dirimir tales cuestiones. Todo juicio acerca de la utilidad o no de un marco teórico dado sería siempre relativo a la respectiva idea acerca de la tarea historiográfica; presupondría, en definitiva, cicrtas orientaciones de evaluación pre-teóricamente concebidas.

De hecho, la solución convencionalista es necesariamente inestable y termina siempre conduciendo a una cncrucijada: o bien avanzar en esta dirección relativista, proclamando abiertamente la completa arbitrariedad de su tipología (incluida su propia idea del «lenguaje poético en general"); o bien retroceder hacia una fundamentación analítica de la misma y postular la propia metahistoria como una suerte de metavocabulario trans-trópico de validez universal (dado que enraizaria en los fundamentos «naturales» de la especie). Optar por uno de estos dos puntos de vista extremos resulta ineludible dentro de los marcos de los sistemas de pensamiento formalistas-antigenéticos, como White mismo nos muestra.

[E] formalismo] daba sentido a los procesos históricos con base a una distinción entre formas inferiores y superiores de vida, on la existencia natural e histórica [aspecto que, como vimos, no aparece en White]. Pero, como consideraba que las coherencias formales en términos de las cuales especificaba esa distinción eran intemporales en esencia, el formalismo no tenía nin- 
gún principio con el cual explicar su evolución... Igual que el enfoque mecanicista de la historia, el enfoque formalista tenía que elegir entre la conclusión de que las coherencias formales que discernia en la historia aparecian y desaparecian al azar, y la de que representaban la eterna recurrencia del mismo conjunto de coherencias formales a lo largo del tiempo. De su consideración no era posible derivar ningún desarrollo realmente cvolutivo. Así, el mecanicismo y el formalismo por igual imponian por último una elección entre la incoherencia total de los procesos historicos (pura contingencia) y su coherencia total (pura determinación) (p. 87).

De ser esto último cicrto, entonces White debió enfrentar una opción similar entre la «pura contingencia» y la «pura determinaciôn». Sin embargo, a White lc resulta imposible aceptar tal conclusión en su literalidad: decidirse por una actitud irónica radical hubiera tornado insostenible su taxonomia; pero sostener su incondicionada validez contradiría su proclamado relativismo (sobre el que se asienta, además, toda su empresa por trascender el mismo). White terminará así, como veremos, oscilando entre ambas alternativas.

\section{Metahistoria e Indefinicion}

A continuación analizaremos las razones por las cualcs White no podia optar por una de ambas altemativas radicales y sostenerla consistentemente.

Volvamos, pues, a la cuestión original. El punto que White pretende sustanciar es, como vimos, la afirmación de que «la ironía es sólo una de una serie de perspectivas posibles», todas ellas igualmente legitimas, y no la única verdadera. El éxito o el fracaso de toda su metahistoria dependería de su logro o no en sostener convincentemente este postulado.

Podemos entonces suponer, prima facie, que dicha conclusión pretende ser cicrta, $y$, por supuesto, su opuesta falsa. Esto implicaría que todos los discursos histo- riográficos serían igualmente válidos, pero no así todos los metahistoriográficos ${ }^{18}$. Tal postulado puede ser inferido de algunas de sus afirmaciones.

Fue grande la tentación de correlacionar las cuatro formas básicas de conciencia historica con tipos correspondientes de personalidad, pero decidí no hacerlo por dos razones. Una es que la psicología se encuentra actualmentc en el mismo estado de anarquía conceptual en que estaba la historia en el siglo xIx. En mi opinión, es probable que un análisis del pensamiento psicológico contemporáneo revele el mismo conjunto de estrategias interpretativas (cada una presentada como la ciencia defiritiva de su tema) que he descubierto en mi análisis del pensamiento histórico. Es decir, como la psicología no ha alcanzado todavía el tipo de sistematización que caracteriza las ciencias físicas, sino que sigue dividida entre «escuelas» de interpretación en conflicto, probablemente hubiera ter. minado por duplicar los descubrimientos a que llegué en mi estudio del pensamiento histórico (p. 409).

Se siguen de aquí dos conclusiones. Primero, que el resto de los elementos que tomó para construir su taxonomia habían superado previamente el estadio pre-paradigmático que él atribuye a la psicología. Segundo, que este hecho le permitió evitar, según dice, la duplicación de sus descubrimientos al nivel histórico. Significa, pues, que la teoría de los tropos no se aplicaría al nivel metahistórico; es decir, que la perspectiva irónica de White no sería sólo «una de una serie» de perspectivas metahistoriográficas posibles ${ }^{19}$.

De hecho, ésta sería la única forma de sustentar su conclusión primera, es decir, rechazando todo tipo de relativismo al nivel de un segundo orden de conceptualización. El marco formalista terminaría entonces subordinando y relegando al nivel meramente historiografico su perspectiva irónica. Esto supondría introducir una asimetría entre niveles de discurso (cs decir, lo que sería válido a un primer orden de 
discurso, no lo sería a un segundo orden del mismo) a fin de producir una clausura metacrítica. Pero ello no podía representar una solución viable para White, puesto que terminaría entonces reproduciendo, aunque a distintos niveles, lo que criticara a lo historiadores narrativistas, es decir, consagrando la ironia (relativa, al nivel histórico) como una verdad absoluta al nivel metahistórico.

La otra alternativa, pues, era llevar la actitud irónica hasta sus consecuencias finales. Pero esto conduciría a White a lo que quiso evitar cuando rechazó incorporar la psicología a su estudio: la «duplicación de los descubrimientos", lo cual lo envolvería en una suerte de regreso al infinito. En cfecto, cn este último caso obtendríamos la metafirmación siguiente:

La afirmación de que "la ironia es sólo una de una serie de perspectivas posibles" representa sólo una de una serie de perspectivas posibles.

El resultado habria sido que la ironía whiteana se habría visto «trascendida» del mismo modo que él pretendió «trascender la perspectiva irónica de la historia; es decir, en tal caso, no tendría White ya argumentos que oponer a los que sostuvieran a la perspectiva wirónica» de la historia como la única forma «realista» de ver el mundo. La única forma de evitarlo seria buscar, a su vez, el «trascender» la ironía de la ironía de la ironía trasladando la actitud irónica a un tercer nivel de conceptualización $^{20}$, y así al infinito. Una vez más, dentro de los marcos del pensamiento formalista el término lógico de este círculo eterno consistiría en introducir la idea de una asimetria en los diversos nivcles de discurso y adoptar dogmáticamente (al nivel que fuere) a un determinado punto de vista como el único verdadero.

Pero la naturaleza problemática de una concepción escéptica radical aparece más claramente cuando consideramos el carác- ter social de la empresa historiográfica. La actitud irónica en este respecto plantea no sólo el problema de la relación sujeto-objeto, sino que concierne principalmente a los fundamentos intersubjetivos de la empresa historiográfica. Los «tropos» de los que habla White no pueden ser meras convenciones: ellos deben existir realmente puesto que explicarían cómo un discurso determinado puede circular socialmente $y$, en definitiva, regular los mecanismos de consagración de un historiador determinado.

Sostengo que el vínculo entre un historiador determinado y su público potencial se forja en un nivel de conciencia preteórico y especificamente lingüístico. $Y$ esto sugiere que el prestigio de que gozan un historiador o filósofo de la historia determinados dentro de un público específico es atribuible al terreno lingüistico precríticamente proporcionado sobre el cual se realiza la prefiguración del campo histórico (p. 408) ${ }^{21}$.

La metahistoria de White cabría comprenderla así como un rechazo a la idea de una racionalidad universal, postulando, en cambio, la existencia de redes autónomas varias de sentidos compartidos intersubjetivamente. Ia pertenencia o no a una determinada comunidad linguística puede, eventualmente, ser resultado de una decisión arbitraria, fundada sobre supuestos de naturaleza moral o estética. Pero la exis. tencia objetiva misma de los paradigmas como tales no estaría aquí, en principio, en cuestión. La teoria de los tropos de White sôlo cobra sentido como una exposición de los modos de existencia de los diversos tipos de competencias comunicativas.

En este terreno, la extension de la actitud irónica hacia arriba (es decir, al nivel metahistoriográfico) conllevaría hacia abajo un regreso al infinito similar al analizado anteriormente, en este caso, produciendo una fragmentación del campo historiográfico. La conclusión natural de este proceso 
sería el solipsismo. El csccpticismo radical conduciría asi a la máxima de Gorgias de que no sólo no existe verdad alguna sino que, de existir, tampoco podría comunicarse. Incluso todo «decisionismo" (del tipo postulado por White) carecería entonces de significación social puesto que no cabría conccbir ya vínculos reales que conectaran las decisiones individuales. El único modo de romper este círculo es postular, pues, la efectiva existencia de objctos tales como los tropos (con las consecuencias sustancialistas que ello conlleva) y que los mismos pueden ser conocidos analíticamente. Pero aquí la actitud irónica se desvanecería en la forja dogmática.

Digamos, por otra parte, que si no fuera así, si no se sostuviera dogmáticamente que los tropos existen realmente, tampoco la actitud «irónica» opuesta, es decir, la idea de que la metahistoria que White construye es «sólo una de las perspectivas posibles" entre cuatro variantes posibles fundamen- tales cuya existencia queda postulada por ella misma contendría ya significado alguno. Es decir, la perspectiva irónica contradice la argumentación formalista tanto como también la presupone.

En definitiva, ello explica por qué White no puede decidirse por ninguna de las dos opciones (la dogmática o la escéptica) y termina, como dijimos, oscilando entre ambas, al precio, sin embargo, de renunciar a intentar fundamentar tcóricamente su propia perspectiva metahistoriográfica. De todos modos, y a pesar de las aporías a las que tal llamado *giro lingüístico" pueda conducir y los debates que el mismo pueda suscitar, no puede ser más plausible el hecho de que el público de habla castellana pueda, por fin, tener un acceso directo a los mismos a través de uno de sus más importantes y lúcidos representantes. Metahistoria de White está indudablemente destinada a seguir siendo una fuente estimulante de ideas, y también de controversias, por mucho tiempo más. 


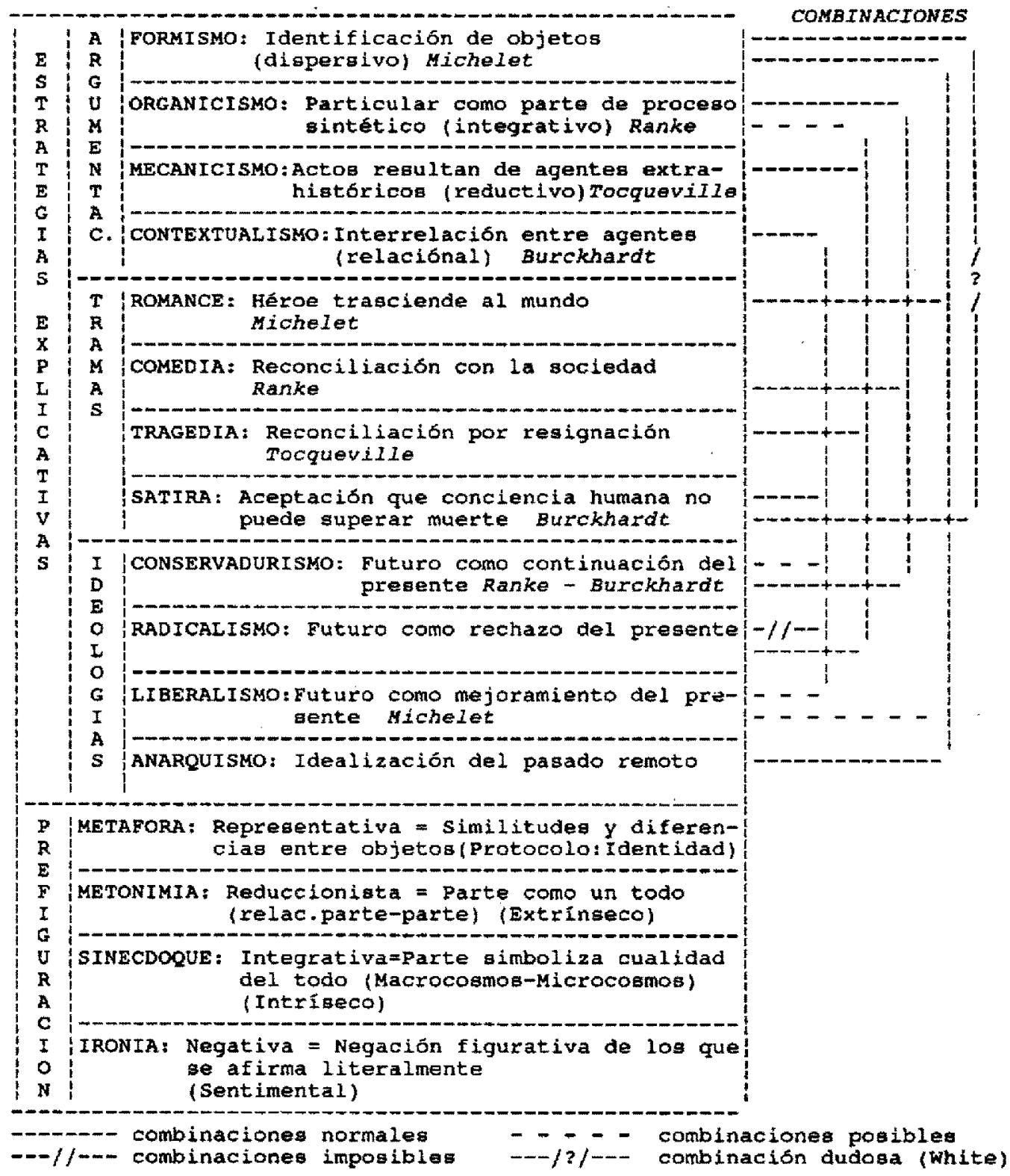




\section{NOTAS}

- I Iayden White (1928) es profesor en el programa de Hixtor of Consciounness de la Universidad de California en Santa Cruz. Además de la ya mencionada Metahistory. The Historical Imagination in Nineteenth-Century Furope (John Hopkins Press, Baltimote and London, 1973), sus abras mas importantes son: Tropics of Discourse (John Hopkins Press, Baltimore and London, 1978) y the Content of the Form (John Hopkins Press, Battimore and London, 1982). Tambicn colaboró en numerosas publicaciones periódicas y en diversas recopilaciones de textos.

2 En realidad diversas son las escuelas del pensamiento histórico que, desde comienzos de siglo, vienen postulando que el material documental necesita ser primero aprefigurados según un paradigma determinado a fin de tornarlo susceptible de integrarse en cornstrucciones narrativas del lipo de las que los historiadores crean. Pero White habria sido el primero en abordar la tarca do construir un aparato teórico-metodológico capaz de fijar conceptualmentc un nivel de discurso cuya existencia afimaron otros antes que él (Collingwood lo bautizó como «imaginación a prioriw), o sospecharon, sin alcanzar, sin embargo, a definir en sus componentes extructurales.

"Para figurarse "Io que realmente ocurrio" en el pusado... il historiador tiene que prefigurar como un posible objeto de oonocimiento todo el conjunto de sucesos registrados en los documentos. Este acto prefigurativo es poético, en la medida en que es precognitivo y precríticom $(p .40)$.

${ }^{4}$ Los tipos de xargumentación formal (tormista, organicista, mecanicista y contextualista) White los toma de lo que Stephen Pepper llamara shipótesis del mundos (ver Worlt Hipotheses, Berkeley, University of California Press, 1942), S. Pepper incluye otras tres "hipótesis det mundo" a las que considera sinadecuadasm: animista, mística y metafísica. La tipologia de wimplicaciones ideológicasw (conservadurismo, liberalismo, radicalismo y anarquismo) surge de K. Mannheim (ver Ideologia y ulopía, México, FCE, 1987). Los tipos de opuesta en tramas (romance, comedia, tragedia y sátira) son de Northrop Frye (ver Anatomy of Criticism, Princeton, Princeton University Press, 1973).

${ }^{5}$ Esto significa pretender dictar reglas a la realidad; en estè cuso, a la práctica historiogräfica. La obra de P. Veyne, Cómo se escribe la historia, sería un ejemplo de tal falacia normativista entre los sostenedores del narrativismo. White tanbién se distanciaría asi de aquellas "grandes narrativas" metahistoriográficas, de corte teologizante, que ven la historia conpleta de la historiografia occidental conto un curso lincal (o, a veces, penoso e intrincado) hacia la cmergencia de alguna lorma de conciencia historica proclamada como la última y verdadera. Aun las perspectivas más relativistas, e incluso escépticas, son susceptibles de ser eluboradas bajo tal forma teleológica, como lo muestra la obra de Paul Ricoeur, Temps et recit.

- La filosofia de la historia, decía entonces, dehe proveer «hipotesis tentativas necesarias para toda accionn, como patroncs ciclicos o regularidades que sugieran ael carácter esencialmente acumulativo de la experiencia humana*, $H$. White, ubn Kaldun in Workl Philusuphy of History". Comparatives Studits in Soctery and History 2 (1989), pp. 122-23.

H. Kellner, «A Bedrock of Order: Hayden White's Linguistic Humanism», History and Sociery, Beiheft. 19, p. 29

Para comentarios criticos sobre la obra de White ver la serie de seis ensayos-reseñas aparecidos en History and Theory, Beibeft, 19, 1980; tambien las de John Nelson, publicadas en Fistory and Theory, 14, 1975, pp. 74-91, y de Michael Ermath, American Historical Review; 80, 1975, pp. 506-527. Ver tambien Dominick LaCapra, «A Poetics of Historiography; Hayder White's Tropucs of Discourses, en Rethinking Intellectual Histony Ithaca y Londres, Cornell University Press, 1983, pp. 23-71, y la respuesta de $H$. White, *The Absurdist Moment in Contemporary Literary Inistory", Tropics of Discourse, pp. 261-282. Este mismo debate subyace a las ponencias de ambos publicadas en D. LaCupra y S. Kaplan (comps), Modern European Intellewal Hislory: Ratppratsals and New Perspectives, Ithaca y Londres, Comell University Press, 1982. Una buena reseña de las polémicas en torno a la obra de White se encuentra en Lym Hunt (comp.), The New Cultural History, Berkeley, University of California Press, 1989. Otras resenas interesantes son las de E. Tows, intellectual History after the Liguistic Turn: The Autonony of Meaning and the Irreducibility of Experiences, American Historical Review, 92, 1987, pp. 879-907, y la resena-ensayo de W. Bouwsma sobre LaCapra-Kaptan. op. cil., aparecida en Histon and Theon, 23, 1984 , pp. 229-236.

${ }^{3}$ Quizá la única excepción sea el estudio de Kellner ya citado, quien intenta descubrir la critica que la propia obra contiene en sí misma; aunque, en este caso, el tono general de la misma resulta claramente laudatorio.

is Aquí habremos de concentramos, por razones de espacio disponible, en los problemas de tipo metodolúgico que tsta vbra prestinta, dejando de lado el análisis de los estudios concretos que White realiza y que constituyen el cuerpo central del libro.

"White menciona la existencia de un wciclo de las actitudes morales", en el cual, por ejemplo. da conedia es logicamente posterior a la tragediay (p. 119). Ph. Pomper centra st critica de la ubra de White en la ausencia de un principio dinámico capaz de dar cuenta de la evolucion historica de los diversos estifos que analiza (xTypologies and Cycles in Intellectual History", History and Theory, Beiheft, 19, pp. 30-38). Para M. Mandelbaum el ahisloricismo de 
su tipología constituye su mayor debilidad, puesto que conduce inevitablemente al relativismo (*The Pressuppositions of Metahison, History and Theory, Bcheft, 19, p. 49); F. Jameson, cn cambio, no ve en tal carencia una prucba de que tal metahistoria sea uerrada», sino simplemente revelaria la necesidad de completar la misma orcintegrándola a la historia social de la cultura en su conjuntom (aFigural Relativism, or The Poetics of I listoriographys, The ldeologies of Theory. Essays 1971-1986, Minneapolis, University of Minnesotat Press, 1989, vol. 1, p. 165)

I2 La tcoria de los tropos fuc concebida originariamente por N. Frye como sun estudio sistemático de las causas formalcs del arte" (Anatomy of Criticion, p. 29).

1. Fncontramos aquí el único patrỏn legitimo, para White, para juzgar la historiografia de un periodo dado, "El campo historiografico", dice, eparecería ser rico y creativo exactamente en la medida en que genera muchas diferentes descripciones posibles de un mismo conjunto de sucesos» (p. 265).

is White deja constancia de ello, aunque sôlo en sus nolas a pie de página; pocas de tales redefinicinnes, por ofra parte, intenta justificarlas práctica o teóricamente. Sobre discusiones acerca de lats categorías de analisis que White emplea, vor F. Jameson, op cit. y $\$$. Gearbant, "History as criticism: The Dialogue of Iistory and Literatures, Diacritics, Fall, 1987. pp. $56-65$.

15 «Me doy cuenta de quc, al usar la terminología y clasificación de estructuras de trama (plot) de Frye, me expongo a la crítica de los teoricos de la literatura que se opunen a sus esfuerzos laxonómicos, o bien tienen otras taxonomias que proponer er lugar de la suya. No pretendo sugerir que las categorias de Frye sean las únicas posibles para clasificar generos, modis, mythoi y demás en literatura, pero me han resultado especialmente utiles para el análisis de las obras históricas: (n. 6, p. 19).

is «Apelar al valor heuristico no convencerá a sus críticos", dice Ph. Pumper, "de que el sistema de clasificación de White sea algo más que un método inteligente, pero arbitrarion (Pomper, op. cit, p. 33).

17 Ver. J. Nelson, op. cit, p. 80.

s* Scgún E. Golob, acl vigor de su argumento histórico no deja duda respecto de su propia convicción que esta contando la verdad, dicicndo wie es eigentlich gevesen, corrigiendo errores de otros historiadores\%. En definitiva, Whitc supone que tal kestructura profunda... realmente existey (E. Golob, «The Irony of Nihilism», History and Throry, Bciheft, 19, pp. 61 y 63). La afirmación de Golob necesita una precisión. En White se distinguen claramente dos niveles, cl historiográfico y el metahistoriográfico. Este autor de nir gún modo pretende discutir errores de los historiadores que analiza respecto de lo que acealmente pasos en la historia. Pero la afirmación de Golob sí vale al nivet metahistoriografico. White efectivamente afirma hechos y debate posturas sobre to que crealmentc vcurrió» en la historia de la historiografía occidental a lo laryo del siglo pasado.

is Esta es, de hecho, la postura adoptada por Frye (de quien White toma su teuría de los tropos). Según Frye, su teoría de los tropos señalaba una distinción radical entre la crítica literaria (que, por $5 u$ intermedio, adquiria status de disciplita cientifica) y la literatura (ver Anatomy of Criticism. pp. 17 y ss.). Ph. Pomper sospecha una actitud similar en White, para quien nos encontrariamos en wel lin de un ciclo de desarrollo asociado al inevitable fracaso de una proto-ciencia por superar ef pluralismo lingüísticow (Ph. Pormpcr, «Typologies and Cyclesm, p. 36).

7o que nos daria la meta-afirmación de que da afirmación de que la metahistoria whiteana es sôlo una de una serie de perspectivas posibles, es solo una de las perspectivas posibles*, con lo que se sugeriat que ésta pueda no ser absolutamente arhitraria y conllevar algún contenido de werdad".

2 En "The Burden of History». White postulaba ya, en 1966, su idea de los kestilosw como soportes últimos de la inteligibilidad histórica [Histen and Theorys 5 (1966), p. 130]. 


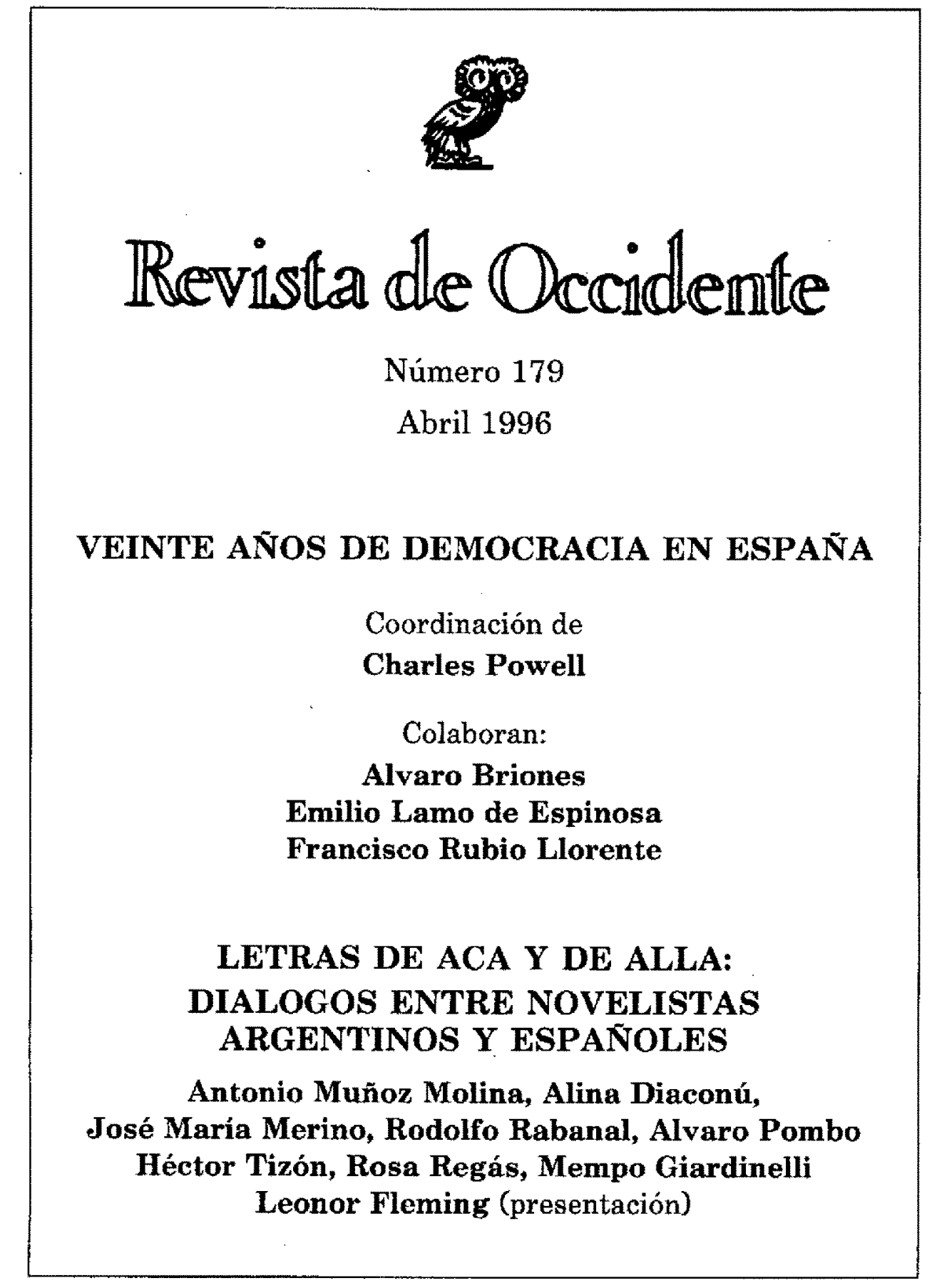

